\title{
Predictive Ability of Preoperative PT-INR and Postoperative MCP1 for Post-hepatectomy Liver Failure
}

\author{
SAYAKA ARISAKA ${ }^{1}$, RYUSEI MATSUYAMA ${ }^{1}$, KOKI GOTO $^{1}$, YUSUKE SUWA ${ }^{1}$, \\ RYUTARO MORI $^{1}$, DAISUKE MORIOKA ${ }^{1}$, MASATAKA TAGURI ${ }^{2}$ and ITARU ENDO ${ }^{1}$ \\ ${ }^{1}$ Department of Gastroenterological Surgery, Yokohama City University, Yokohama, Japan; \\ ${ }^{2}$ Department of Biostatistics, Yokohama City University, Yokohama, Japan
}

\begin{abstract}
Background: We sought a diagnostic tool using perioperative variables that might predict post-hepatectomy liver failure (PHLF). Patients and Methods: In 68 patients undergoing major hepatectomy, data on inflammatory markers and coagulation factors were prospectively collected and were compared between patients with International Study Group of Liver Surgery definition grade B/C PHLF (LF group) and those without LF (non-LF group). Results: Preoperatively, the LF group $(n=9 ; 13.2 \%)$ had a lower platelet count and a disintegrin-like and metalloproteinase with thrombospondin type 1 motifs 13 (ADAMTS13) activity and a higher prothrombin time-International Normalized Ratio (PT-INR) than the non-LF group. On postoperative day 1 , the LF group had significantly higher serum interleukin 6 (IL6), C-C motif chemokine ligand 2 (CCL2), and IL10 levels than the non-LF group. The logistic regression model that included preoperative PT-INR and CCL2 on postoperative day 1 predicted grade B/C PHLF with $100 \%$ sensitivity and $89.8 \%$ specificity. Conclusion: Our findings suggest that the combination of preoperative PT-INR and CCL2 on postoperative day 1 can predict PHLF earlier and precisely after major hepatectomy.
\end{abstract}

Although hepatectomy can currently be performed quite safely due to remarkable refinements in surgical techniques, perioperative management, and surgeon experience, the morbidity and mortality rates after major hepatectomy remain $30-45 \%$ and $3-5 \%$, respectively (1-5). Posthepatectomy liver failure (PHLF) particularly easily leads to mortality. Therefore, various models using preoperative

This article is freely accessible online.

Correspondence to: Itaru Endo, 3-9 Fukuura, Kanazawa-ku, Yokohama 236-0004, Japan. Tel: +81 457822650, Fax: +81 457829161, e-mail: endoit@yokohama-cu.ac.jp

Key Words: Major hepatectomy, post-hepatectomy liver failure, predictive model, inflammatory marker, coagulation factor. variables have been devised to predict PHLF (6-9). However, PHLF cannot be completely prevented using these existing models.

The International Study Group of Liver Surgery (ISGLS) proposed a definition of PHLF in 2011 (10) that had reliable prognostic value, as ISGLS grade B/C PHLF often led to severe morbidity or mortality (11). However, the diagnosis of PHLF based on the ISGLS definition as well as other established criteria, such as the 50-50 criteria (12) or Peak ${ }^{B i l i}>7$ criteria (13), requires about 5 days to have elapsed after hepatectomy, by which point it may be too late to intervene (10-13). Even though treatments of PHLF itself have not been established, the outcomes of hepatectomy might be improved by prevention or earlier intervention if a diagnostic tool for predicting PHLF much earlier than postoperative day (POD) 5 can be constructed.

LF is considered multifactorial and often associated with sepsis (14-16). Immediate responses of various inflammatory and coagulation markers, such as interleukin-6 (IL6) or plasminogen activator inhibitor-1 (PAI1), have been reportedly involved in the development of severe sepsis and significantly correlated with the treatment outcomes (17-21). Furthermore, such immediate responses have been observed in the early phase after hepatectomy and are significantly associated with the development of PHLF (22-24).

We considered that such immediate responses after hepatectomy have a significant role in developing PHLF, as well as predictive value for PHLF, especially in combination with preoperative variables. In the present study, we investigated the chronological changes in perioperative variables, including inflammatory cytokines, coagulation, and fibrinolytic factors, in order to construct a diagnostic model for predicting PHLF precisely and much earlier than POD5.

\section{Patients and Methods}

The perioperative variables of 68 patients undergoing major hepatectomy, including right or left hemi-hepatectomy and right or left trisectionectomy, between October 2013 and October 2015 at the Yokohama City University Hospital were investigated. The 
in vivo $34: 1255-1263(2020)$

Table I. Clinical characteristics of patients in the groups with post-hepatectomy liver failure (LF) and without (non-LF).

\begin{tabular}{|c|c|c|c|c|c|}
\hline Variable & & Total $n=68$ & LF group $n=9$ & Non-LF group $n=59$ & $p$-Value \\
\hline Age, years & Mean \pm SD & $62 \pm 16$ & $66 \pm 10$ & $61 \pm 16$ & 0.751 \\
\hline Gender, n (\%) & Male & $43(63 \%)$ & $6(67 \%)$ & $37(63 \%)$ & 0.819 \\
\hline \multirow[t]{5}{*}{ Disease, n (\%) } & Cholangiocarcinoma & $32(47 \%)$ & $5(56 \%)$ & $27(46 \%)$ & \\
\hline & Hepatocellular carcinoma & $11(16 \%)$ & $1(11 \%)$ & $10(17 \%)$ & \\
\hline & Liver metastasis & $13(19 \%)$ & $2(22 \%)$ & $11(19 \%)$ & 0.801 \\
\hline & LDLT donor & $5(7 \%)$ & $1(11 \%)$ & $4(7 \%)$ & \\
\hline & Other & $7(10 \%)$ & 0 & $7(12 \%)$ & \\
\hline \multirow[t]{4}{*}{ Liver function } & ICG-R15, \% & $12.9 \pm 5.9$ & $16.5 \pm 7.5$ & $12.3 \pm 5.5$ & 0.128 \\
\hline & Serum total bilirubin, $\mathrm{mg} / \mathrm{dl}$ & $0.6 \pm 0.3$ & $0.9 \pm 0.67$ & $0.61 \pm 0.21$ & 0.151 \\
\hline & Serum albumin, $\mathrm{g} / \mathrm{dl}$ & $3.3 \pm 0.5$ & $3.0 \pm 0.5$ & $3.4 \pm 0.4$ & 0.030 \\
\hline & PT-INR & $1.1 \pm 0.1$ & $1.21 \pm 0.15$ & $1.08 \pm 0.08$ & 0.009 \\
\hline Preoperative cholangitis, $\mathrm{n}(\%)$ & Yes & $18(26 \%)$ & $3(33 \%)$ & $15(25 \%)$ & 0.616 \\
\hline \multirow[t]{4}{*}{ Preoperative treatment, $\mathrm{n}(\%)$} & Chemotherapy & $25(37 \%)$ & $5(56 \%)$ & $20(24 \%)$ & 0.209 \\
\hline & Portal vein embolization & $33(49 \%)$ & $5(56 \%)$ & $28(48 \%)$ & 0.651 \\
\hline & Preoperative biliary drainage & $23(34 \%)$ & $4(44 \%)$ & $19(32 \%)$ & 0.470 \\
\hline & Anticoagulant therapy & $9(13 \%)$ & $1(11 \%)$ & $8(14 \%)$ & 0.840 \\
\hline \multirow[t]{5}{*}{ Preoperative planning, mean \pm SD } & Resection volume, $\mathrm{ml}$ & $510 \pm 239$ & $615 \pm 289$ & $494 \pm 229$ & 0.222 \\
\hline & Resection rate, $\%$ & $44 \pm 15$ & $53 \pm 13$ & $42 \pm 15$ & 0.054 \\
\hline & Remnant liver volume, $\mathrm{ml}$ & $634 \pm 238$ & $502 \pm 106$ & $654 \pm 247$ & 0.054 \\
\hline & Predictive score & $32 \pm 22$ & $49 \pm 13$ & $30 \pm 22$ & 0.012 \\
\hline & rICGK & $0.08 \pm 0.03$ & $0.06 \pm 0.01$ & $0.08 \pm 0.03$ & $<0.001$ \\
\hline \multirow[t]{4}{*}{ Procedure, n (\%) } & Right hemi-hepatectomy & $31(46 \%)$ & $4(44 \%)$ & $27(46 \%)$ & 0.941 \\
\hline & Left hemi-hepatectomy & $27(40 \%)$ & $2(22 \%)$ & $25(42 \%)$ & 0.250 \\
\hline & Right trisectionectomies & $4(6 \%)$ & $1(11 \%)$ & $3(5 \%)$ & 0.474 \\
\hline & Left trisectionectomies & $6(9 \%)$ & $2(22 \%)$ & $4(7 \%)$ & 0.128 \\
\hline \multirow{3}{*}{ Additional procedure, $\mathrm{n}(\%)$} & Pancreatico-duodenectomy & $5(7 \%)$ & 0 & $5(9 \%)$ & 0.364 \\
\hline & Biliary tract reconstruction & $27(40 \%)$ & $5(56 \%)$ & $22(37 \%)$ & 0.297 \\
\hline & Blood vessel reconstruction & $24(35 \%)$ & $6(67 \%)$ & $18(31 \%)$ & 0.034 \\
\hline \multirow[t]{3}{*}{ Intraoperative factors } & Operative time, $\min$ & $656 \pm 230$ & $859 \pm 362$ & $625 \pm 188$ & 0.078 \\
\hline & Bleeding, $\mathrm{ml}$ & $1407 \pm 1020$ & $3321 \pm 3404$ & $1115 \pm 702$ & 0.189 \\
\hline & $\mathrm{RCC}$ transfusion, $\mathrm{ml}$ & $329 \pm 748$ & $1307 \pm 1615$ & $180 \pm 340$ & $<0.001$ \\
\hline \multirow[t]{5}{*}{ Morbidity, n (\%) } & Total & $19(28 \%)$ & $5(56 \%)$ & $14(24 \%)$ & 0.047 \\
\hline & Infection & $11(16 \%)$ & $3(33 \%)$ & $8(14 \%)$ & 0.310 \\
\hline & Bleeding & $6(9 \%)$ & $2(22 \%)$ & $4(7 \%)$ & 0.128 \\
\hline & Thrombosis & 0 & 0 & 0 & 0.694 \\
\hline & Other & $4(6 \%)$ & 0 & $4(7 \%)$ & 0.421 \\
\hline Length of hospital stay, days & $\operatorname{Mean} \pm \mathrm{SD}$ & $21 \pm 20$ & $47 \pm 43$ & $17 \pm 3$ & 0.025 \\
\hline In-hospital mortality & Frequency, $\%$ & $3(4 \%)$ & $3(33 \%)$ & 0 & $<0.001$ \\
\hline
\end{tabular}

LDLT: Living donor liver transplantation; ICG-R15; ICG retention rate at 15 minutes; PT-INR: prothrombin time-International Normalized Ratio; rICGK: Indocyanine green kinetics value for the liver remnant [=ICG K (ICG plasma disappearance rate)×remnant liver rate]; RCC: red-blood cell concentrate. Bold values show significance.

patient characteristics are summarized in Table I. Twenty-five patients $(37 \%)$ underwent pre-hepatectomy chemotherapy. Twentyseven patients $(40 \%)$ had biliary reconstruction. Twenty-four patients $(35 \%)$ had concomitant vascular resection and reconstruction. Five patients $(7 \%)$ underwent concomitant pancreaticoduodenectomy. Written-informed consent, as approved by the Human Research Review Committee of Yokohama City University Hospital (no. 131107018), was obtained from all patients prior to their enrollment in our study.

Preoperative management. We judged hepatectomy to have been performed with acceptable safety when the following criteria were fulfilled: Indocyanine green kinetics value for the liver remnant (rICGK) (9) of more than 0.05 and more than $300 \mathrm{ml}$ of functional liver remnant. The liver and tumor volume were measured by computed tomographic volumetry (25). Portal vein embolization (PVE) was performed before right hepatectomy and before right or left trisectionectomy.

Blood sampling and measurement of pro-/anti-inflammatory markers and coagulation/fibrinolysis factors. Peripheral blood samples were obtained before the operation and on POD1, 3, and 5 . In addition to usual laboratory tests in daily clinical practice, the following pro- and anti-inflammatory cytokines, coagulation, and fibrinolytic factors were measured at each time point: IL1 $\beta, \mathrm{C}-\mathrm{C}$ motif chemokine ligand 2 (CCL2), IL6, activities of a disintegrinlike and metalloproteinase with thrombospondin type 1 motifs 13 (ADAMTS13), and von Willebrand factor (vWF). 

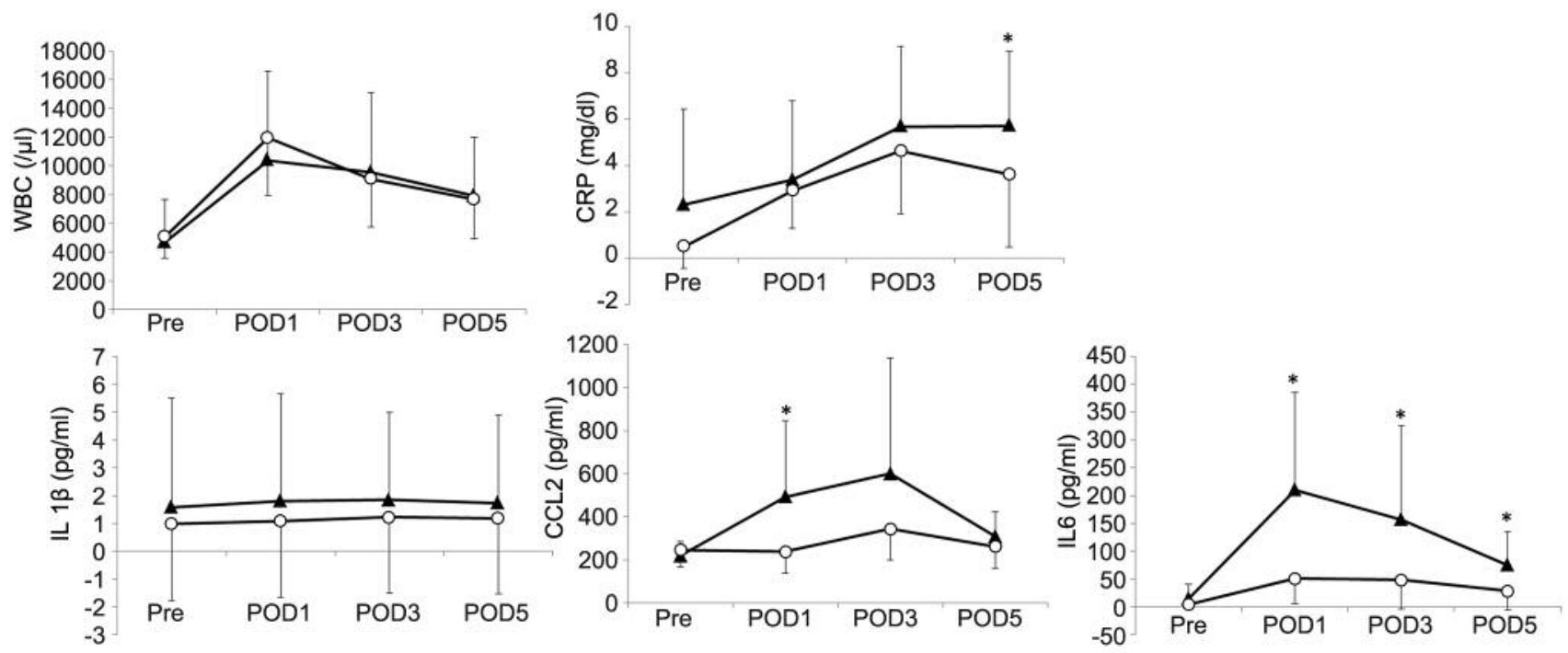

Figure 1. Changes in the inflammatory markers in the groups with (triangles) and without (circles) post-hepatectomy liver failure. The values are expressed as the mean \pm standard deviation. WBC: White blood cell count; CRP: C-reactive protein; IL1 $\beta$ : interleukin 1 $\beta ; C C L 2: C$-C motif chemokine ligand 2; IL6: interleukin 6; POD: postoperative day; Pre: pre-operative. *Significantly different at $p<0.05$.

The serum levels of IL6 were quantified using a two-step sandwich chemiluminescence enzyme immunoassay method. The serum levels of IL1 $\beta$ (Quantikine HS human IL-1 $\beta$ Immunoassay; R\&D Systems, Minneapolis, MN, USA) and CCL2 (Quantikine Human MCP-1 Immunoassay; R\&D Systems) were quantified using enzyme-linked immunosorbent assays. ADAMTS13 activity was measured using a chromogenic substrate (26). The level of vWF activity was measured using the fixed-platelet aggregation method. The prothrombin time international normalized ratio (PT-INR) was measured using a method designed by Quick (HemosIL RecombiPlasTin; Japan, Tokyo, Japan). Plasma fibrinogen levels were measured using the Clauss method (HemosIL Fib, Japan). Plasma fibrin and fibrinogen degradation products-E (FDP-E) levels were measured using a latex photometric immunoassay (LPIA FDPE; LSI Medience, Tokyo, Japan). These assays were conducted in accordance with the manufacturer's instructions.

PHLF was diagnosed according to the ISGLS definition (10). The above-stated perioperative variables were compared between patients with ISGLS grade B/C PHLF (LF group) and those without LF.

Statistical analyses. Statistical analyses were performed using the SPSS statistical software version 22.0.0 (IBM, Armonk, NY, USA). Categorical variables were compared using the chi-squared test. Continuous variables are expressed as the mean \pm standard deviation, and differences were assessed by the Mann-Whitney $U$-test Correlation coefficients were calculated with Spearman's rank correlation test when necessary. To determine the influence of different variables on the outcome, a logistic regression analysis was performed. $p$-Values of less than 0.05 were considered statistically significant. To identify the most predictive combination among promising preoperative and POD1 markers, a receiver operating characteristic (ROC) analysis was performed using bivariate logistic regression.

\section{Results}

Incidence of PHLF. PHLF was diagnosed in $10(14.7 \%)$ patients (Table I): Grade A in one (1.5\%); grade B in five (7.4\%); and grade $\mathrm{C}$ in four $(5.9 \%)$. Thus, the 68 patients were divided into clinically relevant LF $(n=9)$ and non-LF $(n=59)$ groups.

Clinical characteristics. The results of a comparison between the LF and non-LF groups are shown in Table I. Preoperatively, the LF group had poor nutritional status, as indicated by low serum albumin, and prolonged coagulation, as indicated by high PT-INR. The application of preoperative interventions, such as chemotherapy, PVE, or biliary drainage, did not differ markedly between the groups. The resection rate was higher $(p=0.054)$, and functional liver remnant based on the computed tomographic volumetry was marginally lower $(p=0.054)$ in the LF group. In the LF group, the Hyogo University predictive score (8) was higher and the rICGK (9) was significantly lower than in the non-LF group. Concomitant vascular resection and reconstruction was significantly more common in the LF group than in the non-LF group. The operative time and amount of bleeding did not differ markedly between the groups. The volume of intraoperative transfusion of red-blood cell concentrate (RCC) was significantly larger in the LF group than in the non-LF group. The LF group showed significantly more frequent morbidity, defined as postoperative complications with a Dindo-Clavien classification of grade 3 or worse (27), and mortality than the non-LF group. Grade B/C PHLF led to mortality in three of nine $(33 \%)$ patients. One 

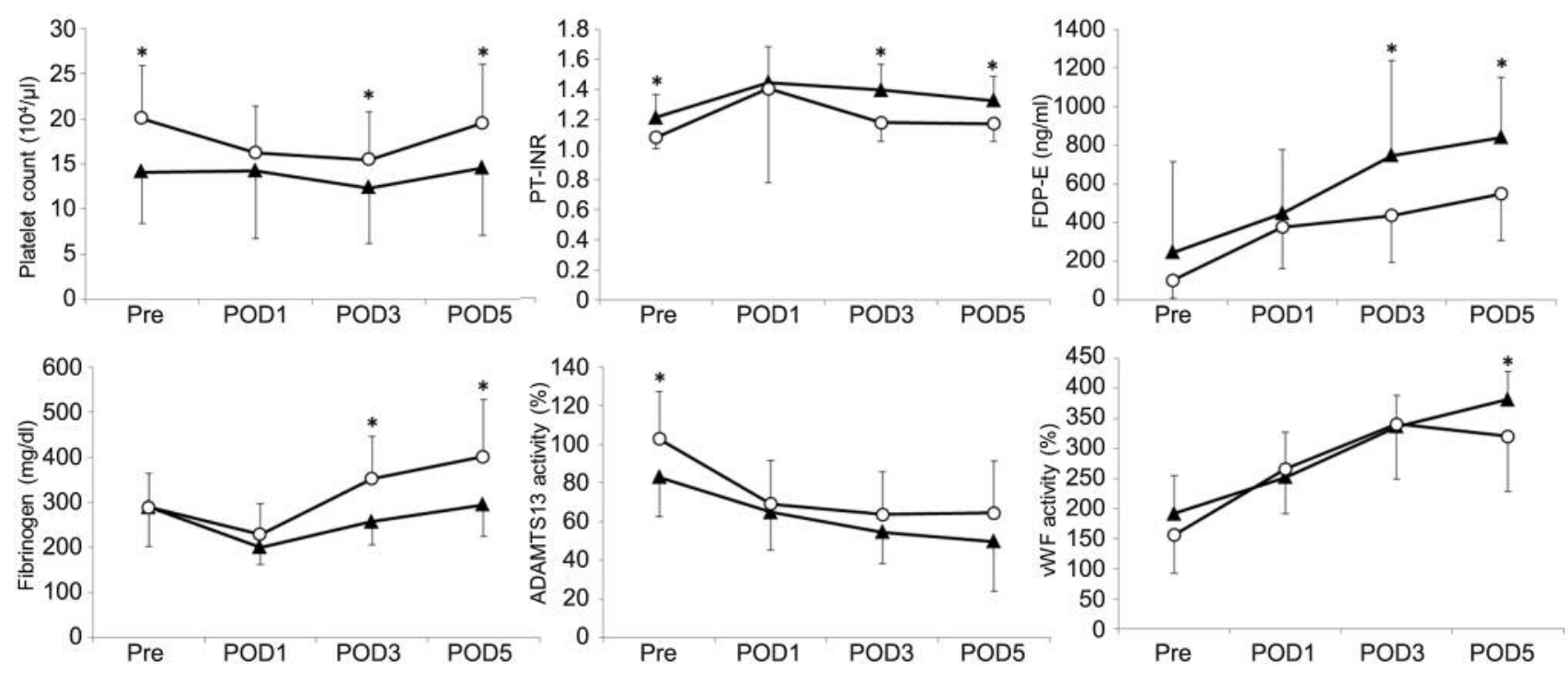

Figure 2. Changes in coagulation and fibrinolytic factors in the groups with (triangles) and without (circles) post-hepatectomy liver failure. The values are expressed as the mean \pm standard deviation. PT-INR: Prothrombin time-international normalized ratio; FDP-E: fibrin and fibrinogen degradation products-E; ADAMTS13: a disintegrin-like and metalloproteinase with thrombospondin type 1 motifs 13; vWF: von Willebrand factor; Pre: pre-operative; POD: postoperative day. *Significantly different at $p<0.05$.

patient with grade C PHLF died of severe infection following PHLF. One patient with grade B PHLF died of sepsis due to liver abscess. Another patient with grade B PHLF died of massive intraperitoneal bleeding.

Inflammatory markers. The preoperative inflammatory markers were quantitatively similar for the two groups (Figure 1). However, the levels of CCL2, IL6, and IL10 on POD1 were significantly higher in the LF group than in the non-LF group. In the LF group, the IL6 and IL10 levels peaked at POD1, and the CCL2 level peaked at POD3. No marked difference in the level of these markers was observed on POD5, except for IL6, which was still significantly higher at POD5 in the LF group than in the non-LF group. The white blood cell count and IL1 $\beta$ level did not differ markedly between the groups at any time points.

Coagulation and fibrinolytic factors. The preoperative platelet count and ADAMTS13 activity were significantly lower and the PT-INR significantly higher in the LF group than in the non-LF group (Figure 2). Although no differences were observed at POD1, the differences reached significance again on POD3 and thereafter. Furthermore, the FDP-E on POD3 and 5 and vWF activity on POD5 were higher in the LF group than in the non-LF group, although these factors did not differ significantly between the groups until POD1.

Construction of predictive models. ROC analyses were performed for variables that showed significant differences between the two groups in order to determine the cut-off value for discriminating between the groups (Table II). The following variables were therefore selected as the strongest indicators of grade B/C PHLF among the pre-, intra-, and immediately postoperative variables: rICGK, volume of RCC during surgery, and total bilirubin (T-Bil) on POD1. The preoperative platelet count and T-Bil on POD1 had high specificity, while the rICGK, RCC volume, CCL2 and T-Bil values on POD1 had the highest sensitivity (88.9\%).

To further improve the sensitivity and specificity, combination analyses were performed using bivariate logistic regression, with bivariate combination considered statistically valid based on the sample size and the incidence of PHLF. Combinations correlating significantly with each other were excluded. Combinations that were not independent of each other were also excluded. The Youden index of each combination is shown in Table III. The combination of preoperative PT-INR and CCL2 on POD1 gave the largest Youden index (0.898), indicating that this combination had the strongest ability to predict grade $\mathrm{B} / \mathrm{C}$ PHLF at POD1.

Figure 3 shows the cut-off value calculated by the Youden index, which is illustrated by the red line. The formula for the cut-off line for predicting grade B/C PHLF was as follows: (Preoperative PT-INR $)+(0.00079 \times$ CCL2 on POD 1$)=1.37$. Nine out of 15 patients $(60 \%)$ above this line developed PHLF. This predictive model had a sensitivity of $100 \%$, specificity of $90 \%$, positive predictive value of $60 \%$, and negative predictive value of $100 \%$. 
Table II. A receiver operating characteristics analysis of the preoperative and postoperative day 1 variables.

\begin{tabular}{|c|c|c|c|c|c|c|}
\hline Variable & & AUC & Cut-off value & $95 \% \mathrm{CI}$ & Sensitivity & Specificity \\
\hline \multirow[t]{6}{*}{ Preoperative } & Predictive score & 42.65 & 0.762 & $0.617-0.908$ & $77.8 \%$ & $65.5 \%$ \\
\hline & rICGK & 0.06 & 0.880 & $0.759-1.000$ & $88.9 \%$ & $86.4 \%$ \\
\hline & Serum albumin, $g / d l$ & 2.85 & 0.725 & $0.536-0.914$ & $55.6 \%$ & $89.8 \%$ \\
\hline & Platelet count, $10^{4} / \mu 1$ & 12.25 & 0.755 & $0.576-0.935$ & $55.6 \%$ & $93.2 \%$ \\
\hline & PT-INR & 1.135 & 0.770 & $0.555-0.986$ & $77.8 \%$ & $78.0 \%$ \\
\hline & ADAMTS13 activity, $\%$ & 94 & 0.727 & $0.559-0.895$ & $77.8 \%$ & $62.7 \%$ \\
\hline Intra-operative & $\mathrm{RCC}$ transfusion, $\mathrm{ml}$ & 140 & 0.845 & $0.711-0.997$ & $88.9 \%$ & $71.2 \%$ \\
\hline \multirow[t]{4}{*}{ POD1 } & IL6, pg/ml & 106.5 & 0.791 & $0.562-1.000$ & $77.8 \%$ & $91.5 \%$ \\
\hline & $\mathrm{CCL} 2, \mathrm{pg} / \mathrm{ml}$ & 241.5 & 0.805 & $0.650-0.960$ & $88.9 \%$ & $59.3 \%$ \\
\hline & AST, IU/1 & 438 & 0.712 & $0.487-0.937$ & $66.7 \%$ & $76.3 \%$ \\
\hline & T-Bil, mg/dl & 2.95 & 0.929 & $0.853-1.000$ & $88.9 \%$ & $94.9 \%$ \\
\hline
\end{tabular}

AUC: Area under the receiver operating characteristics curve; CI: confidence intervaI; rICGK: indocyanine green kinetics value for the liver remnant [=ICG K (ICG plasma disappearance rate)×remnant liver rate]; PT-INR: prothrombin time-international normalized ratio; ADAMTS13: a disintegrinlike and metalloproteinase with thrombospondin type 1 motifs 13; RCC: red-blood cell concentrate; IL6: interleukin 6; CCL2: C-C motif chemokine ligand 2; AST: aspartate aminotransferase; T-bil: total bilirubin. Predictive score [ $=-84.6+0.933 \times$ resection rate+1.11 $\times$ ICGR $15+0.999 \times a g e](8)$.

Table III. A receiver operating characteristics analysis using a bivariate logistic regression analysis of all combination with preoperative and markers on postoperative day 1 (POD1).

\begin{tabular}{|c|c|c|c|c|c|c|c|c|c|c|c|}
\hline & & \multicolumn{5}{|c|}{ Preoperative } & \multirow{2}{*}{$\frac{\text { Intra-operative }}{\mathrm{RBC}}$} & \multicolumn{4}{|c|}{ POD1 } \\
\hline & & rICGK & Alb & Plt & PT-INR & ADAMTS 13 & & IL6 & CCL2 & AST & T-Bil \\
\hline \multirow[t]{6}{*}{ Preoperative } & Predictive score & $\mathrm{a}$ & $\mathrm{b}$ & 0.655 & 0.741 & $\mathrm{c}$ & 0.709 & $\mathrm{c}$ & 0.571 & 0.475 & $\mathrm{c}$ \\
\hline & rICGK & & $\mathrm{c}$ & 0.780 & 0.71 & 0.736 & 0.744 & $\mathrm{c}$ & 0.744 & 0.71 & 0.838 \\
\hline & $\mathrm{Alb}$ & & & 0.686 & $\mathrm{c}$ & $\mathrm{c}$ & $\mathrm{c}$ & $\mathrm{c}$ & 0.616 & 0.616 & $\mathrm{c}$ \\
\hline & Plt & & & & 0.72 & 0.601 & 0.71 & 0.838 & 0.761 & 0.635 & 0.864 \\
\hline & PT-INR & & & & & 0.744 & 0.797 & $\mathrm{~b}$ & 0.898 & 0.821 & $\mathrm{~b}$ \\
\hline & ADAMTS13 & & & & & & 0.659 & $\mathrm{c}$ & 0.633 & 0.505 & c \\
\hline Intraoperative & $\mathrm{RCC}$ transfusion & & & & & & & $\mathrm{b}$ & $\mathrm{a}$ & $\mathrm{c}$ & $\mathrm{b}$ \\
\hline \multirow[t]{3}{*}{ POD1 } & IL6 & & & & & & & & $\mathrm{b}$ & 0.744 & $\mathrm{~b}$ \\
\hline & CCL2 & & & & & & & & & $\mathrm{c}$ & 0.753 \\
\hline & AST & & & & & & & & & & 0.821 \\
\hline
\end{tabular}

rICGK: Indocyanine green kinetics value for the liver remnant [=ICG K (ICG plasma disappearance rate)×remnant liver rate]; Alb: albumin; Plt: platelet count; PT-INR: prothrombin time-international normalized ratio; ADAMTS13: a disintegrin-like and metalloproteinase with thrombospondin type 1 motifs 13; RCC: red-blood cell concentrate; IL6: interleukin 6; CCL2: C-C motif chemokine ligand 2; AST: aspartate aminotransferase;

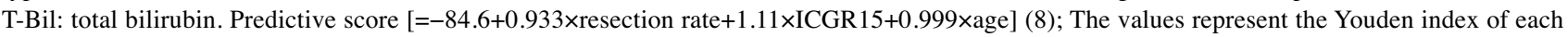
combination. ${ }^{a}$ Combinations that had strong correlations with each other $(r>0.8)$. ${ }^{b}$ Combinations that had medium correlations with each other $(\mathrm{r}>0.4)$. ${ }^{\mathrm{c} C o m b i n a t i o n s ~ t h a t ~ w e r e ~ n o t ~ i n d e p e n d e n t ~ o f ~ e a c h ~ o t h e r ~ a c c o r d i n g ~ t o ~ a ~ b i v a r i a t e ~ l o g i s t i c ~ r e g r e s s i o n ~ a n a l y s i s ~}(p>0.1)$.

\section{Discussion}

The present study showed that the incidence of grade $\mathrm{B} / \mathrm{C}$ PHLF was significantly associated with reduced platelet count and ADAMTS13 activity and increased PT-INR in the preoperative period, and with increased CCL2 and IL6 levels on POD1. These findings corroborated the notion that preoperative increased coagulation and postoperative excessive inflammation were significantly associated with the development of PHLF. Furthermore, the present study demonstrated that the predictive model combining the preoperative PT-INR value and the CCL2 value at POD1 had the strongest ability to predict PHLF, suggesting that the combination of several markers indicative of the coagulation status and immediate inflammatory response may be useful for predicting PHLF earlier and more precisely than existing models.

In addition to the existing models using preoperative variables alone (6-9), numerous preoperative indicators have been reported as promising for predicting or preventing PHLF (28-32). Furthermore, intraoperative factors, such as the need for blood transfusion during surgery (30), have been reported 


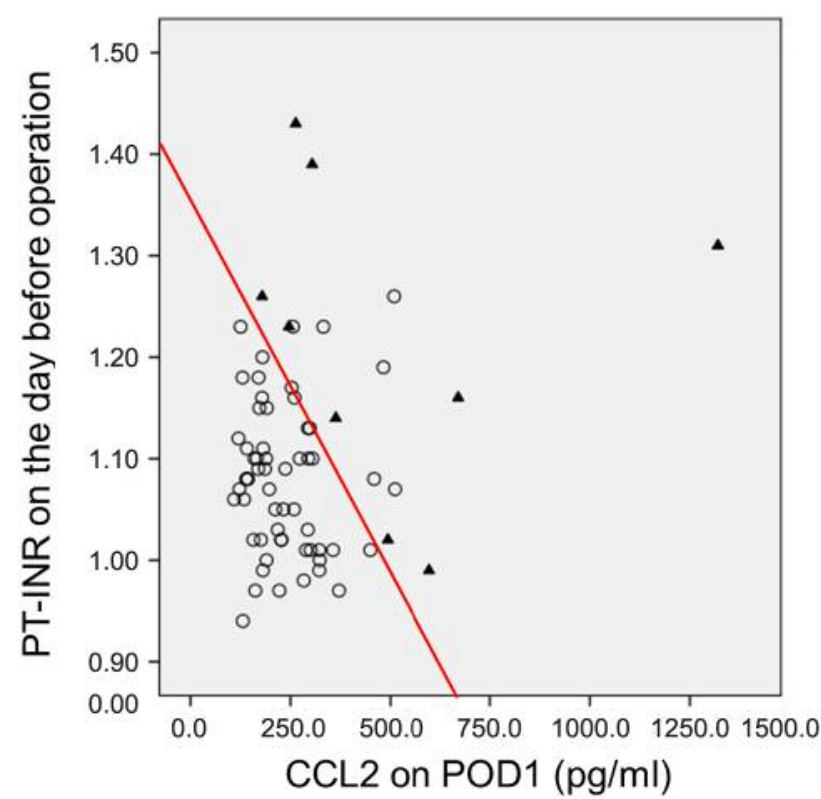

Figure 3. The combination of preoperative prothrombin timeInternational Normalized Ratio (PT-INR) and C-C motif chemokine ligand 2 (CCL2) on postoperative day 1 in the groups with (triangles) and without (circles) post-hepatectomy liver failure. The straight line represents the formula for predicting grade $B / C$ post-hepatectomy liver failure. Nine out of 15 patients (60\%) above this line developed post-hepatectomy liver failure.

to be significantly associated with PHLF. In addition, immediate postoperative factors have been considered to affect the incidence of PHLF significantly $(4,5,14,23,33,34)$. Based on these findings, PHLF is considered to be brought about by underlying conditions as well as other factors (i.e. pre-, intra-, and immediate postoperative variables).

In brief, the etiology of PHLF is considered multifactorial as well as multiphasic. However, existing models have not included variables at different time phases. We therefore attempted to combine time-phasically different variables to predict PHLF more precisely than the existing models. Although our most promising model, the combination of preoperative PT-INR and CCL2 on POD1, did not include any intraoperative variable, the amount of RCC transfusion during surgery, which was significantly associated with grade $\mathrm{B} / \mathrm{C}$ PHLF in the present study, was significantly correlated with the CCL2 level on POD1. Thus, the intraoperative events were considered to be reflected in our model. Furthermore, several other combinations, such as the preoperative platelet count and IL6 on POD1, preoperative platelet count and T-bil on POD1, and rICGK and T-bil on POD1, yielded a high Youden index almost equal to that of the most predictive model. These findings support the reasonableness of our idea of combining variables from different time phases.
CCL2 is a chemokine produced by and endothelial cells that promotes the migration of monocytes/macrophages (35). The increased expression of CCL2 was reported to correlate with postoperative complications and organ dysfunction following hepatectomy $(36,37)$. Furthermore, liver expression of CCL2 was reported to promote fibrosis and to be significantly correlated with either accompanying neutrophil infiltration or disease severity in a model of nonalcoholic steatohepatitis (38-40). In other words, CCL2 strongly affects liver injury and regeneration by its ability to induce the infiltration of neutrophils into the liver parenchyma as well as to promote fibrosis. Thus, controlling the CCL2 expression or excessive accumulation of polymorph nuclear leukocytes in the liver may help resolve PHLF.

Although only bivariate combinations were attempted in the present study due to the sample size and the rate of PHLF occurrence, the present study results suggested the promise of several other markers. ADAMTS13 is a specific cleaving protease for vWF. Reduced activity of ADAMTS13 has been shown in patients with liver schirrous (41) and acute LF (42). In fact, reduced ADAMTS13 activity in the preoperative period was significantly associated with PHLF in the present study. In addition, IL6 is well known to be correlated with liver injury/regeneration after hepatectomy (43). Indeed, an increased serum IL6 level was significantly associated with PHLF in the present study. Therefore, we are currently constructing a prospective database to enable the combination of three or more variables.

Although some substances, such as prostaglandin $\mathrm{E}_{1}$ (44), have been reported to be effective for treating PHLF, established treatments for PHLF itself have not yet been reported. However, we feel that the earlier identification of PHLF is very important and useful for several reasons. As stated above, the development of PHLF is considered to be multifactorial as well as multiphasic. Thus, earlier intervention based on the risk stratification for PHLF before a definitive diagnosis of PHLF is obtained may help improve the survival outcomes of hepatectomy. Furthermore, the meticulous correction of trivial changes that are usually overlooked in daily practice may be of significant aid in preventing PHLF in high-risk patients. As such, our attempt to diagnose PHLF much earlier than POD5 seems quite useful in terms of the availability of earlier intervention and risk stratification for PHLF.

This study had several limitations. Firstly, the sample size was very small. Furthermore, the present study cohort was heterogenous in terms of the indications for hepatectomy, background liver status, and preoperative treatments, such as biliary drainage, PVE, anticoagulation for thrombotic diseases, and various pre-hepatectomy chemotherapy used. Ideally, the influence of these variables should be assessed individually; however, the small sample size did not allow 
for such an investigation. Secondly, the inflammatory markers and coagulation factors were assessed only in serum in the present study. The changes in the expression of these markers in the liver itself should have also been assessed. However, serial liver sample extraction seemed not only impractical but also quite invasive and risky. We therefore abandoned it. Thirdly, it was only possible to examine bivariate combinations in the present study. As stated above, the combination of three or more variables may enable a more accurate prediction than our most promising model.

However, despite these limitations, our predictive model has higher sensitivity and specificity than previous ones, which supports the validity of our idea to construct models using variables in different time phases.

In conclusion, the combination analyses of preoperative coagulation factor and immediate postoperative inflammatory cytokines seems effective for predicting PHLF earlier and more precisely than existing models. We feel that our concept of combining multiphasic variables in order to predict PHLF earlier and more precisely than the existing models is valuable.

\section{Conflicts of Interest}

This research did not receive any specific grant from funding agencies in the public, commercial, or not-for-profit sectors. The Authors declare no conflicts of interest in regard to this study.

\section{Authors' Contributions}

I.E., R.M and Y.S. designed the study. S.A., Y.S. and K.G. acquired the data. S.A., R.M., R.M., M.T. and I.E. analyzed and interpreted the data. S.A. wrote the draft. D.M. and I.E. revised the article critically.

\section{References}

1 Poon RT, Fan ST, Lo CM, Liu CL, Lam CM, Yuen WK, Yeung $\mathrm{C}$ and Wong $\mathrm{J}$ : Improving perioperative outcome expands the role of hepatectomy in management of benign and malignant hepatobiliary diseases: analysis of 1222 consecutive patients from a prospective database. Ann Surg 240(4): 698-708, 2004. PMID: 15383797. DOI: 10.1097/01.sla.0000141195.66155.0c

2 Jarnagin WR, Gonen M, Fong Y, DeMatteo RP, Ben-Porat L, Little S, Corvera C, Weber S and Blumgart LH: Improvement in perioperative outcome after hepatic resection: analysis of 1,803 consecutive cases over the past decade. Ann Surg 236(4): 397-406, 2002. PMID: 12368667. DOI: 10.1097/01.SLA. 0000029003.66466.B3

3 Laurent C, Sa Cunha A, Couderc P, Rullier E and Saric J: Influence of postoperative morbidity on long-term survival following liver resection for colorectal metastases. Br J Surg 90(9): 1131-1136, 2003. PMID: 12945082. DOI: 10.1002/ bjs.4202

4 Vibert E, Pittau G, Gelli M, Cunha AS, Jamot L, Faivre J, Benitez CC, Castaing D and Adam R: Actual incidence and long-term consequences of posthepatectomy liver failure after hepatectomy for colorectal liver metastases. Surgery 155: 94105, 2014. PMID: 24694360 .DOI: 10.1016/j.surg.2013.05.039.

5 Kenjo A, Miyata H, Gotoh M, Kitagawa Y, Shimada M, Baba H, Tomita N, Kimura W, Sugihara K and Mori M: Risk stratification of 7,732 hepatectomy cases in 2011 from the National Clinical Database for Japan. J Am Coll Surg 218(3): 412-422, 2014. PMID: 24468222. DOI: 10.1016/j.jamcollsurg.2013.11.007.

6 Okamoto E, Kyo A, Yamanaka N, Oriyama T, Tomoda F and Kyo A: Prediction of the safe limits of hepatectomy by combined volumetric and functional measurements in patients with impaired hepatic function. Surgery 95(5): 586-592, 1984. PMID: 8031659. DOI: 10.1007/978-1-4615-2604-9_24.

7 Imamura H, Sano K, Sugawara Y, Kokudo N and Makuuchi M: Assessment of hepatic reserve for indication of hepatic resection: decision tree incorporating indocyanine green test. $\mathbf{J}$ Hepatobiliary Pancreat Surg 12: 16-22, 2005. PMID: 15754094. DOI: $10.1007 / \mathrm{s} 00534-004-0965-9$

8 Yamanaka N, Okamoto E, Kuwata K and Tanaka N: A multiple regression equation for prediction of posthepatectomy liver failure. Ann surg 200(5): 658-663, 1984. PMID: 6486915. DOI: 10.1097/00000658-198411000-00018.

9 Nagino M, Kamiya J, Nishino H, Ebata T, Arai T and Nimura Y: Two hundred forty consecutive portal vein embolization before extended hepatectomy for biliary cancer: surgical outcome and long-term follow-up. Ann Surg 243: 364-372, 2006. PMID: 16495702. DOI: 10.1097/01.sla.0000201482.11876.14

10 Rahbari NN, Garden OJ, Padbury R, Brooke-Smith M, Crawford M, Adam R, Koch M, Makuuchi M, Dematteo RP, Christophi C, Banting S, Usatoff V, Nagino M, Maddern G, Hugh TJ, Vauthey J-N, Greig P, Rees M, Yokoyama Y, Fan ST, Nimura Y, Figueras J, Capussotti L, Büchler MW and Weitz J: Posthepatectomy Liver failure: a definition and grading by the International Study Group of Liver Surgery (ISGLS). Surgery 149: 713-724, 2011. PMID: 21236455. DOI: 10.1016/j.surg. 2010.10.001

11 Skyzypczyk C, Truant S, Duhamel A, Langlois C, Boleslawski E, Koriche D, Hebbar M, Fourrier F, Mathurin P and Pruvot FR: Relevance of the ISGLS definition of posthepatectomy liver failure in early prediction of poor outcome after liver resection: Study on 680 hepatectomies. Ann Surg 260(5): 865-870, 2014. PMID: 25243550. DOI: 10.1097/SLA.0000000000000944

12 Paugam-Burtz C, Janny S, Delefosse D, Dahmani S, Dondero F, Mantz J and Belghiti J: Prospective validation of the "fiftyfifty" criteria as an early and accurate predictor of death after liver resection in intensive care unit patients. Ann Surg 249(1): 124-128, 2009. PMID: 19106687. DOI: 10.1097/SLA. 0b013e31819279cd

13 Mullen JT, Ribero D, Reddy SK, Donadon M, Zorzi D, Gautam S, Abdalla EK, Curley SA, Capussotti L, Clary BM and Vauthey $\mathrm{J}-\mathrm{N}$ : Hepatic insufficiency and mortality in 1,059 noncirrhotic patients undergoing major hepatectomy. J Am Coll Surg 204(5): 854-862, 2007. PMID: 17481498. DOI: 10.1016/j.jamcollsurg. 2006.12.032

14 Dhainaut JF, Marin N, Mignon A and Vinsonneau C: Hepatic response to sepsis: interaction between coagulation and inflammatory processes. Crit Care Med 29(7 Suppl): S42-47, 2001. PMID: 11445733. DOI: 10.1097/00003246-200107001-00016

15 Gando S: Microvascular thrombosis and multiple organ dysfunction syndrome. Cirt Care Med 38: S35-42, 2010. PMID: 20083912. DOI: 10.1097/CCM.0b013e3181c9e31d 
16 Levi M and van der Poll T: Inflammation and coagulation. Crit Care Med 38: S26-34, 2010. PMID: 20083910. DOI: 10.1097/CCM.0b013e3181c98d21

17 Uusitalo-Seppala R, Koskinen P, Leino A, Peuravuori $\mathrm{H}$, Vahlberg T and Rintala EM: Early detection of severe sepsis in the emergency room: Diagnostic value of plasma C-reactive protein, procalcitonin, and interleukin-6. Scand J Infect Dis 43: 883-890, 2011. PMID: 21892899. DOI: 10.3109/ 00365548.2011 .600325

18 Miguel-Bayarri V, Casanoves-Laparra EB, Pallas-Beneyto L, Sancho-Chinesta S, Martín-Osorio LF, Tormo-Calandín C and Bautista-Rentero D: Prognostic value of the biomarkers procalcitonin, interleukin-6 and C-reactive protein in severe sepsis. Med Intensiva 36: 556-562, 2012. PMID: 22495097. DOI: $10.1016 /$ j.medin.2012.01.014

19 Tschaikowsky K, Hedwig-Geissing M, Braun GG and Radespiel-Troeger M: Predictive value of procalcitonin, interleukin-6, and C-reactive protein for survival in postoperative patients with severe sepsis. J Crit Care 26: 54-64, 2011. PMID: 20646905. DOI: 10.1016/j.jcrc.2010.04.011

20 Palmiere C and Augsburger M: Markers for sepsis diagnosis in the forensic setting: state of the art. Croat Med J 55: 103-114, 2014. PMID: 24778096. DOI: $10.3325 / \mathrm{cmj} .2014 .55 .103$

21 Lorente L, Martín MM, Borreguero-León JM, Barrios Y, SoléViolán J, Ferreres J, Labarta L, Díaz C and Jiménez A: The 4G/4G genotype of PAI-1 polymorphism is associated with higher plasma PAI-1 concentrations and mortality in patients with severe sepsis. PLoS One 10(6): e0129565, 2015. PMID: 26066833. DOI: 10.1371/journal.pone.0129565

22 Kubota T, Takabe K, Yang M, Sekido H, Endo I, Ichikawa Y, Togo S and Shimada H: Minimum sizes for remnant and transplanted livers in rats. J Hepatobiliary Pancreat Surg 4(4): 398-404, 1997.

23 Hasegawa S, Kubota T, Fukuyama N, Kurosawa H, Sekido $\mathrm{H}$, Togo S, Nakazawa $\mathrm{H}$ and Shimada $\mathrm{H}$ : Apoptosis of hepatocytes is a main cause of inducing lethal hepatic failure after excessive hepatectomy in rats. Transplant Proc 31: 558559, 1999. PMID: 10083236. DOI: 10.1016/s00411345(98)01554-1

24 Watanabe K, Togo S, Takahashi T, Matsuyama R, Yamamoto $\mathrm{H}$, Shimizu T, Makino H, Matsuo K, Morioka D, Kubota T, Nagashima Y and Shimada H: PAI-1 plays an important role in liver failure after excessive hepatectomy in the rat. J Surg Res 143(1): 13-19, 2007. PMID: 17655862. DOI: 10.1016/ j.jss.2007.04.041

25 Kubota K, Makuuchi M, Kusaka K, Kobayashi T, Miki K, Hasegawa K, Harihara Y and Takayama T: Measurement of liver volume and hepatic functional reserve as a guide to decision-making in resectional surgery for hepatic tumors. Hepatology 26: 1176, 1997. PMID: 9362359. DOI: 10.1053/ jhep.1997.v26.pm0009362359

26 Kokame K, Nobe Y, Kokubo Y, Okayama A and Miyata T: FRETS-VWF73, a first fluorogenic substrate for ADAMTS13 assay. Br J Haematol 129(1): 93-100, 2005. PMID: 15801961. DOI: $10.1111 / \mathrm{j} .1365-2141.2005 .05420 . \mathrm{x}$

27 Dindo D, Demartines N and Clavien PA: Classification of surgical complecations: A new proposal with evaluation in a cohort of 6336 patients and results of a surgery. Ann Surg 240: 205-213, 2004. PMID: 15273542. DOI: 10.1097/01.sla. 0000133083.54934.ae
28 Tomimaru Y, Eguchi H, Gotoh K, Kawamoto K, Wada $\mathrm{H}$, Asaoka $\mathrm{T}$, Noda $\mathrm{T}$, Yamada D, Ogawa H, Umeshita K, Nagano H, Doki Y and Mori M: Platelet count is more useful for predicting posthepatectomy liver failure at surgery for hepatocellular carcinoma than indocyanine green clearance test. J Surg Oncol 113(5): 565-569, 2016. PMID: 26751258. DOI: $10.1002 /$ jso. 24166

29 Kudo M, Todo A, Ikekubo K and Hino M: Receptor Index via hepatic asialoglycoprotein receptor imaging: Correlation with chronic hepatocellular damage. Am J Gastroenterol 87: 865-870, 1992. PMID: 1615940.

30 Suehiro T, Matsumata T, Shikada Y, Shimada M, Shirabe K and Sugimachi K: Preoperative hyaluronic acid measurement to assess the hepatic functional reserve. Hepatogastroenterology 51(60): 1776-1779, 2004. PMID: 15532824.

31 Chong CC, Wong GL, Chan AW, Wong VW, Fong AK, Cheung Y, Wong J, Lee KF, Chan SL, Lai PB and Chan HL: Liver stiffness measurement predicts high-grade post-hepatectomy liver failure: A prospective cohort study. J Gastroenterol Hepatol 32(2): 506-514, 2017. PMID: 27490702. DOI: 10.1111/jgh.13503

32 Nishio T, Taura K, Koyama Y, Tanabe K, Yamamoto G, Okuda Y, Ikeno Y, Seo S, Yasuchika K, Hatano E, Okajima H, Kaido T, Tanaka S and Uemoto S: Prediction of post-hepatectomy liver failure based on liver stiffness measurement in patients with hepatocellular carcinoma. Surgery 159: 399-408, 2016. PMID: 26209567. DOI: 10.1016/j.surg.2015.06.024

33 Shimada H, Matsuba A, Nimoto S, Fujita H, Nakagawara G and Tsuchiya S: Liver failure after hepatic resection. J Jpn Surg 90: 566-572, 1989. PMID: 2761525.

34 Alkozai EM, Nijsten MW, de Jong KP, de Boer MT, Peeters PMJG, Slooff MJ, Porte RJ and Lisman T: Immediate postoperative low platelet count is associated with delayed liver function recovery after partial liver resection. Ann Surg 251: 300-306, 2010. PMID: 19779326. DOI: 10.1097/SLA. 0b013e3181b76557

35 Yoshimura T, Robinson EA, Tanaka S, Appella E, Kuratsu J and Leonard EJ: Purification and amino acid analysis of two human glioma-derived monocyte chemoattractants. J Exp Med 169: 1449-1459, 1898. PMID: 2926329. DOI: 10.1084/jem.169. 4.1449

36 Kimura F, Shimizu H, Yoshidome H, Ohtsuka M, Kato A, Yoshitomi H, Nozawa S, Furukawa K, Mitsuhashi N, Sawada S, Takeuchi D, Ambiru S and Miyazaki M: Circulating cytokines, chemokines, and stress hormones are increased in patients with organ dysfunction following liver resection. J Surg Res 133: 102-112, 2006. PMID: 16386757. DOI: 10.1016/j.jss. 2005.10.025

37 Strey CW, Marquez-Pinilla RM, Markiewski MM, Siegmund B, Oppermann E, Lambris JD and Bechstein WO: Early postoperative measurement of cytokine plasma levels combined with pre-operative bilirubin levels identify high-risk patients after liver resection. Int $\mathrm{J}$ Mol Med 27: 447-454, 2011. PMID: 21206966. DOI: $10.3892 / \mathrm{ijmm} .2010 .592$

38 Miura K, Yang L, van Rooijen N, Ohnishi H and Seki E: Hepatic recruitment of macrophages promotes nonalcoholic steatohepatitis through CCR2. Am J Physiol Gastrointest Liver Physiol 302(11): G1310-1321, 2012. PMID: 22442158. DOI: 10.1152/ajpgi.00365.2011

39 Seki E, de Minicis S, Inokuchi S, Taura K, Miyai K, van Rooijen $\mathrm{N}$, Schwabe RF and Brenner DA: CCR2 promotes hepatic 
fibrosis in mice. Hepatology 50(1): 185-197, 2009. PMID: 19441102. DOI: 10.1002/hep.22952

40 Degré D, Lemmers A, Gustot T, Ouziel R, Trépo E, Demetter $\mathrm{P}$, Verset L, Quertinmont E, Vercruysse V, Le Moine O, Devière $\mathrm{J}$ and Moreno C: Hepatic expression of CCL2 in alcoholic liver disease is associated with disease severity and neutrophil infiltrates. Clin Exp Immunol 169(3): 302-310, 2012. PMID: 22861370. DOI: 10.1111/j.1365-2249.2012.04609.x

41 Uemura M, Fujimura Y, Matsumoto M, Ishizashi H, Kato S, Matsuyama T, Isonishi A, Ishikawa M, Yagita M, Morioka C, Yoshiji H, Tsujimoto T, Kurumatani $\mathrm{N}$ and Fukui $\mathrm{H}$ : Comprehensive analysis of ADAMTS13 in patients with liver cirrhosis. Thromb Haemost 99: 1019-1029, 2008. PMID: 18521503. DOI: $10.1160 /$ TH08-01-0006

42 Hugenholtz G, Adelmeijer J, Meijers J, Porte RJ, Stravitz RTand Lisman T: An unbalance between von Willebrand factor and ADAMTS13 in acute liver failure: Implications for hemostasis and clinical outcome. Hepatology 58: 752-761, 2013. PMID: 23468040. DOI: $10.1002 /$ hep.26372
43 Sgroi A, Gonelle-Gispert C, Morel P, Baertschiger RM, Niclauss N, Mentha G, Majno P, Serre-Beinier V and Buhler L: Interleukin-1 receptor antagonist modulates the early phase of liver regeneration after partial hepatectomy in mice. PLoS One 6(9): e25442, 2011. PMID: 21980458. DOI: 10.1371/journal. pone. 0025442

44 Natori S, Fujii Y, Kurosawa H, Nakano A and Shimada H: Prostaglandin $\mathrm{E}_{1}$ protects against ischemia-reperfusion injury of the liver by inhibition of neutrophil adherence to endothelial cells. Transplantation 64: 1514-1520, 1997. PMID: 9415549. DOI: $10.1097 / 00007890-199712150-00002$

Received February 21, 2020

Revised March 9, 2020

Accepted March 12, 2020 